\title{
Development and validation of a robust high-performance thin layer chromatographic (HPTLC) method for the analysis of Lovastatin in Higher Basidiomycetous mushrooms
}

\section{Vijay Vardhan Pandey*}

Forest Pathology Discipline, Forest Protection Division, Forest Research Institute, Dehradun (Uttarakhand), India

Vinay Kumar Varshney

Chemistry and Bioprospect Division, Forest Research Institute, Dehradun (Uttarakhand), India

Amit Pandey

Forest Pathology Discipline, Forest Protection Division, Forest Research Institute, Dehradun (Uttarakhand), India

*Corresponding author. E-mail: vijayvardhan1989@gmail.com

\begin{abstract}
Hypercholesteromia is one of the main risk factors of cardiovascular disease, causing high blood pressure and atherosclerosis. This has necessitated development of methods or substances which would reduce cholesterol uptake from the digestive tract or destroy cholesterol by enzymatic reactions. One of the practical approaches to protect the human body from high cholesterol levels is to inhibit the cholesterol-synthesizing ability of the organism. Lovastatin is a metabolite of mold fungi from the different genera. However, its presence has also been detected in fruiting bodies and submerged cultivated mycelia of some species of Higher Basidiomycetous fungus, especially in the species of genus Pleurotus $-P$. ostreatus and $P$. eryngii. We are screening Higher Basidiomycetous mushrooms for identification of commercially recoverable quantities of lovastatin. Since lovastatin quantification in a large number of fungal samples is required, a simple, rapid and accurate analytical method was required. Use of HPTLC for quantitative measurements of lovastatin in fungal biomass has not yet been reported. In the present study a simple, precise, specific and accurate TLC Densitometric method for estimation of lovastatin in Higher Basidiomycetous mushrooms was developed, validated and used for estimation of lovastatin content in the cultured mycelia of Pleurotus spp. The develop method was validated for linearity, accuracy, precision, LOD, LOQ, spiking, robustness as per the ICH guidelines. The $\mathrm{R}_{\mathrm{f}}$ and \% recovery value for Lovastatin 0.52 and 99.15 respectively. Developed analytical methods showed good separation and recovery of Lovastatin.
\end{abstract}

Keywords: Basidiomycetous, HPTLC, Lovastatin, Pleurotus.

\section{Article Info}

DOI:10.31018/jans.v10i3.1868 Received: August 15, 2018 Revised: August 25, 2018 Accepted: August 27, 2018

\section{How to Cite}

Pandey, V.V. et al. (2018). Development and validation of a robust highperformance thin layer chromatographic (HPTLC) method for the analysis of Lovastatin in higher Basidiomycetous mushrooms. Journal of Applied and Natural Science, 10(3): $1059-1062$

\section{INTRODUCTION}

Lovastatin (monacolin K, Mevinolin; Mev) is one of the most interesting fungal secondary metabolites. Lovastatin and related compounds contain a naphthalene ring system, a 13-hydroxylactone and methylbutyric acid. Lovastatin inactive in lactone form is hydrolyzed to the biologically active form i.e. $\beta$-hydroxy acid in the body (Moore et al. 1985) (Fig. 1). These fungal metabolites are competitive inhibitors of 3-hydroxy-3-methylgiutarylCoA reductase (EC 1.1.1.34). This enzyme catalyzes the rate-limiting step in the biosynthesis of cholesterol, the reduction of HMG-CoA to mevalonate (Endo A. 1979; Endo et al. 1985; Goldstein and Brown, 1990; Gunde-cimerman et al. 1993). Thus, Lovastatin and also its analogues are potent hypocholesterolemic and hypolipemic agents and effective substance for treatment of athero- sclerosis and coronary heart disease (Endo A. 1988; Frishman et al. 1989; Gunde-cimerman et al. 1995). Several fungal genera including Aspergillus, Penicillium, Monascus, Paecilomyces, Trichoderma, Scopulariopsis, Doratomyces and Pleurotus were able to synthesize Mevinolin (Endo A et al., 1976; Endo A. 1979; Alberts et al. 1985; Kumagai et al. 1990; Gunde-cimerman et al. 1993).

Various High performance liquid chromatography (HPLC) methods available for development and validation for the analysis of Lovastatin. HPLC is a versatile separation technique and is official in most of the pharmacopeias for determining content uniformity, purity profile, assay values and dissolution rates in unlimited number of monographs. The exact reason for this is availability of HPLC system in almost every laboratory. However, it cannot be denied that more than often, the 
systems are working beyond their capacities and mostly dedicated. Who would like to change a well -running stabilized column and prepare fresh solutions only because few assorted samples even through urgent are required to be analyzed. Analyst usually has the tendency to wait until large number of similar samples is accumulated, even risking the product development work because of non-availability of analytical results. Is not the HPTLC, the answer in such situations-YES? It can simultaneously handle several samples even of divergent nature and composition supporting several analysts at a given time. HPTLC is the most simple separation techniques today available to the analyst. It can be considered a time machine that can speed your work and allows you to do many things at a time usually not possible with other analytical techniques. HPTLC is now truly a modern contemporary of HPLC and GC and continues to be an active and versatile technique in research with large number of publications appearing each year.

In the present investigation, an attempt was made to develop a simple and economical validated HPTLC with greater precision, accuracy and sensitivity for the simultaneous estimation of Lovastatin in pure and extraction forms.

\section{MATERIALS AND METHODS}

Chemicals and reagents: An analytically pure sample of Lovastatin obtained from Hi-media.

Preparation of solutions

Preparation of standard stock solution: The standard Lovastatin $10 \mathrm{mg}$ was weighed accurately and transferred to volumetric flask $10 \mathrm{ml}$. It was dissolved in the $10 \mathrm{ml}$ methanol with the use of sonicator to obtain the final concentration of $1 \mathrm{mg} /$ $\mathrm{ml}$ and the resulting solution was used as working stock solution.

Preparation of sample solution: For the estimation of Lovastatin, $1 \mathrm{ml}$ of prepared standard stock solution dissolved with $9 \mathrm{ml}$ Methanol and we obtained the final concentration of $100 \mathrm{ng} / \mu \mathrm{l}$ for working standard sample solution.

Chromatography: Analysis was performed on 10 $\mathrm{cm} \times 10 \mathrm{~cm}$ HPTLC silica gel $60 \mathrm{~F}_{254}$ plates (Merck, Darmstadt, Germany) with concentrating zone .The TLC plates were saturated with methanol. Activation was done in an oven at $50^{\circ} \mathrm{C}$ for 5 min .Sample and standard zones were applied to the layer as bands by means of a CAMAG (Muttenz Switzerland) Linomat V automated spray -on application equipped with a $100 \mu \mathrm{L}$ syringe (Hamilton, Reno, Nevada, USA).The slit dimension $6 \mathrm{~mm} \times 0.45 \mathrm{~mm}$ and scanning speed of 20 $\mathrm{mm} / \mathrm{sec}$ was employed. Ascending development of the plates, migration distance $60 \mathrm{~mm}$, was performed at $25 \pm 2{ }^{\circ} \mathrm{C}$ with Chloroform:Methanol $(95: 5, v / v)$, as mobile phase in a CAMAG twin trough chamber previously saturated for $20 \mathrm{~min}$. The average development time was $30 \mathrm{~min}$. After development the plates was dried at $50^{\circ} \mathrm{C}$ in an oven for $5 \mathrm{~min}$. Densitometric scanning at $\lambda=238$ $\mathrm{nm}$ was then performed with a CAMAG TLC Scanner-3 equipped with winCAT 1.4.4 software, using a deuterium light source.

Validation of the method: Validation should not be seen separately from the development of a method. It starts from a clearly defined analytical goal, method selection, optimization, and development, which is called prevalidation considerations before arriving at the elaboration of a validation protocol and is the starting point of the actual validation. After performing all the experiments described in the validation protocol, obtained data are evaluated and compared with the acceptance criteria. If all criteria are met, the method can be regarded as valid. In a less-formal approach, some validation data may be incorporated from experiments, which were conducted previously as part of the method development.

The above approach is widely accepted for validation of qualitative HPTLC methods for identification during routine use. It is possible that the validation method in different situations may require some changes in the standard validation protocol. Such changes may include restrictions with respect to relative humidity, waiting times, precision, etc. The validation protocol is a key instrument for structuring, regulating and documenting the validation processes, depending on the quality management system.

\section{RESULTS AND DISCUSSION}

The present study was aimed at development of speedy and cost-effective HPTLC technique for determination of lovastatin as pure and extraction forms. Different combinations of solvent systems in different proportion were tried as mobile phase. However mobile phase consisting of Chloroform: Methanol in the ratio of $95: 5(\mathrm{v} / \mathrm{v})$ was found to be more suitable with $R_{f}$ values of 0.52 , with saturation time of 20 minute based on maximum absorbance for optimum sensitivity. The drug showed good linearity in the range of $100-900$ ng per spot

Table 1. Calibration parameters for lovastatin.

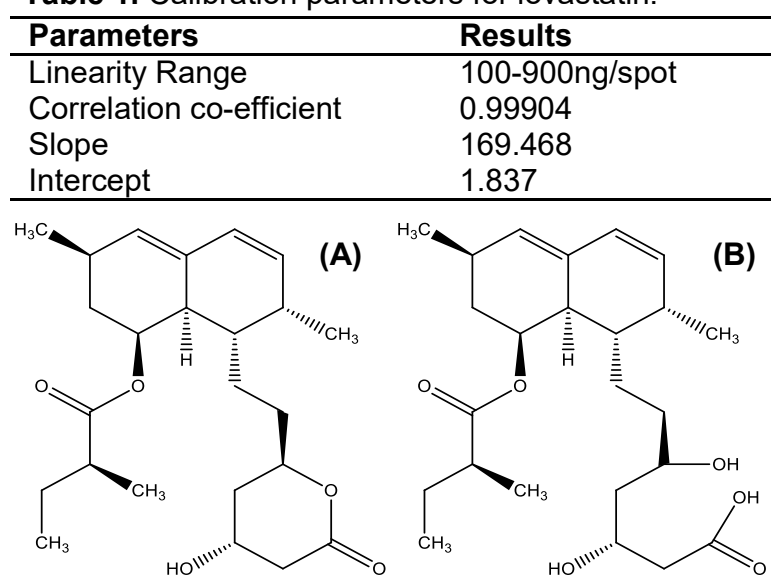

Fig. 1: Different forms of lovastatin (A) Lovastatin with lactone form, (B) Lovastatin with hydroxy acid form. 


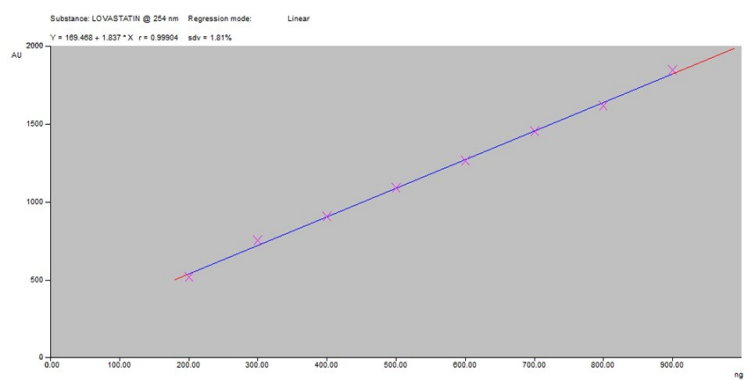

Fig. 2. Linearity vurve of lovastatin.

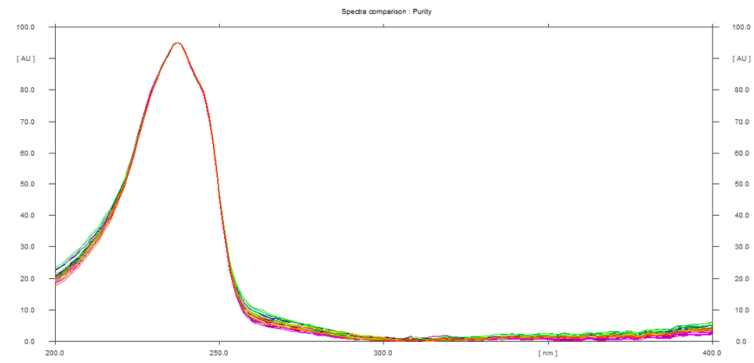

Fig. 4. Overlay absorption spectra of Standard lovastatin.

Table 2. Estimation of standard Lovastatin from its formulations.

\begin{tabular}{llll}
\hline $\begin{array}{l}\text { Formu- } \\
\text { lations }\end{array}$ & $\begin{array}{l}\text { Labeled } \\
\text { amount }(\mathrm{ng})\end{array}$ & $\begin{array}{l}\text { Amount } \\
\text { found }(\mathrm{ng})\end{array}$ & $\begin{array}{l}\% \text { of lovas- } \\
\text { tatin found }\end{array}$ \\
\hline a & 500 & $9.915 \pm 0.105$ & $99.15 \pm 1.05$ \\
$\mathrm{~b}$ & 500 & $9.843 \pm 0.118$ & $98.43 \pm 1.18$ \\
$\mathrm{c}$ & 500 & $9.893 \pm 0.145$ & $98.93 \pm 1.45$ \\
\hline
\end{tabular}

Table 3. Method validation parameters.

\begin{tabular}{ll}
\hline Parameter & Results \\
Instrumental Precision (\%CV) $(\mathrm{n}=9)$ & 0.99 \\
Repeatability $(\% \mathrm{CV})(\mathrm{n}=6)$ & 0.71 \\
Specificity & Specific \\
Accuracy $(\%)$ & $99.15 \pm 1.05$ \\
Linearity Range $(\mathrm{ng} / \mathrm{\mu l})$ & $100-900$ \\
Correlation coefficient & 0.999 \\
\hline
\end{tabular}

with coefficient of correlation value 0.99904 for peak area. From the recovery studies, the accuracy results were within the range of $98.48-99.64 \%$ and were found to be highly accurate. Checked after deliberate alteration of the peaks of interest remained unaffected by small changes of the operational parameters (\%RSD < 2).

The appropriate volume of standard Lovastatin stock solution was prepared and applied on the TLC plates in the range of $1-9 \mu \mathrm{L}$ to give a series of spots covering the range from 100 to $900 \mathrm{ng} /$ spot with the help of microliter syringe and scanned densitometrically at $238 \mathrm{~nm}$. The standard peak - area was calculated for each concentration level and a graph was plotted of standard concentration level and a graph was plotted of standard concentration against the peak area. Calibration parameters are given in table: 1 .

The developed method was validated for specificity, repeatability and accuracy. The method is found to be specific for lovastatin since it resolved the peak of lovastatin

(Rf value $=0.52$ ) in presence of other excipients in

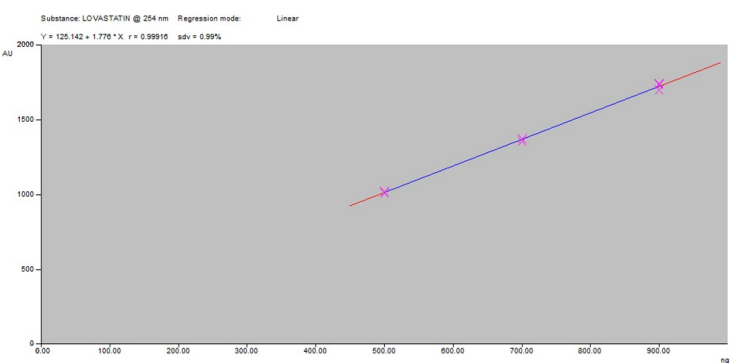

Fig. 3. Precision experiments for lovastatin standard.

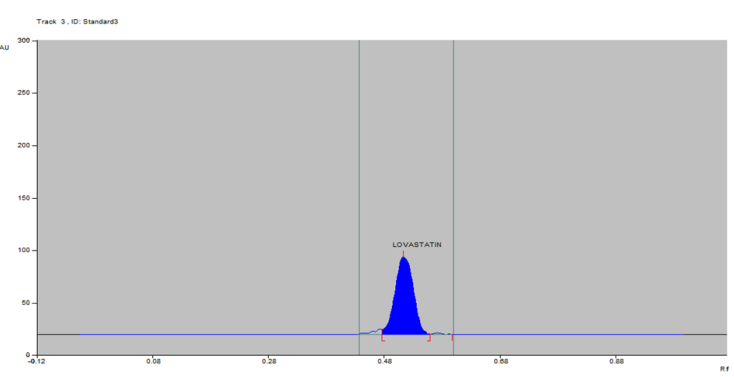

Fig. 5. TLC chromatogram of lovastatin from lovastatin standard.

the standard formulations (Fig. 5). The specificity was also confirmed by overlaying the spectra of standard lovastatin on TLC scanner in UV range (Fig. 4). Linearity range for lovastatin was found to be in range of 100-900ng/spot (Table 1). The correlation coefficient $(r=0.999904) \quad(Y=$ $\left.169.468+1.837^{*} X\right)$ and other method validation parameters are given in table 3 . Prior to the precision of the instruments was checked by repeated scanning of the same spot (500ng, 700ng, 900ng per spot) of lovastatin for three times and the \%CV was found to be 0.99 . Repeatability of the method was checked by analyzing a standard solution of

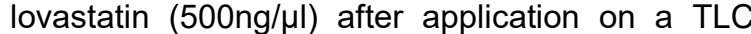
plate $(n=6)$ and the \% CV for peak area was found to be 0.71 . Accuracy of the method was evaluated by carrying out a recovery study. A known concentration of the standard lovastatin solution (500ng/ spot) was added to a pre-analyzed sample solution (500ng/spot), extracted and quantified as mentioned above. The percentage recovery was found to be 99.15 (Table 2).

\section{Conclusion}

An HPTLC method to analyze lovastatin in pure and extraction forms was optimized. The extraction procedure was optimized to stability of the compounds during analysis. The method was validated according to $\mathrm{ICH}$ guidelines. The method was linear in the range 100-900 $\mathrm{ng} / \mu \mathrm{l}$ and had a recovery of $99.15 \%$. Repeatability and accuracy were acceptable. This method can be used to control the quality of lovastatin based products and would allow drug companies to marketing their products containing lovastatin to use an accurate and reliable method of analysis that meets $\mathrm{ICH}$ standards. Based on this method, drug manufacture companies could develop and validate a method for quality control on their commercial products. 


\section{ACKNOWLEDGEMENTS}

The authors are grateful to the Director, Forest Research Institute, Dehradun, for providing necessary research facilities.

\section{REFERENCES}

1. Moore R N., Bigam G., Chan J.K, Hogg A.M., Makashima T.T., VEDERAS J.C. (1985). Biosynthesis of the hypocholesteroletic agent mevinolin by Aspergillus terreus. Determination of the origin of carbon, hydrogen and oxygen atoms by ${ }^{13} \mathrm{C}$ NMR and mass spectrometry. J. Am. Chem. Soc., 107: 3694-3701.

2. Endo A. (1979). Monacolin K, a new hypocholesterolemic agent produced by a Monascus species. J. Antibiot., 32: 852-854.

3. Endo A., Hasumi K, Negishi S. (1985) Monacolins J and $L$, new inhibitors of cholesterol biosynthesis produced by Monascus ruber. J. Antibiot., 38: 420-422.

4. Goldstein J.L., Brown M.S. (1990). Regulation of the mevalonate pathway. Nature, 343: 425-430.

5. Gunde-Cimerman N., Fiedrich J., Cimerman A., Benicki N. (1993) Screening fungi for the production of an inhibitor of HMG CoA reductase: Production of mevinolin by the fungi of the genus Pleurotus. FEMS Microbiol. Lett., 111: 203-206.
6. Endo A. (1988) Chemistry, biochemistry and pharmacology of HMG COA reductase inhibitors. Klin.Wochenschr., 66: 421-427.

7. Frishman W.H., Zimetbaum P., Nadelmann J. (1989) Lovastatin and other HMG-CoA reductase inhibitors. J. Clin. Pharmaacol., 29: 975-982.

8. Gunde-Cimerman N., Cimerman A. (1995). Pleurotus fruiting bodies contain the inhibitor of 3-hydroxy-3methylglutaryl cocnzyme A reductase lovastatin. Exp.Mycol ., 19: 1-6.

9. Endo A., Kuroda M., Tsujita Y. (1976) ML-236A, ML 236B and ML 236C, new inhibitors of cholesterogenesis produced by Penicillium citrinam. J. Antibiot., 29:1346-1348.

10.Alberts A.W., Chen J., Kuron G., Hunt V., Huff J., Huff C., Hoffman C., Rothrock J., Lopez M., Joshua H., Harris E., Patchett A., Monaghan R., Currie S., Stapley E., Albers-Schonberg G., Hensens O., Hirshifield J., Hoogsten K., Liesch J., Springer J. (1980). Mevinolin: A highly potent competitive inhibitor of 3-hydroxy-3-methylglutaryl-coenzyme A reductase and a cholesterol lowering agent. Proc. Nat. Acad. Sci., USA 77: 3957-3961.

11.Kumagai H., Tomoda H., Omura S. (1990). Method of search for microbial inhibitors of mevalonate biosynthesis using animal cells. J.Antibiot., 43: 397-402. 